\title{
Training residents in off-pump coronary artery bypass surgery: A 14-year experience
}

\author{
Michele Murzi, MD, Massimo Caputo, MD, Giuseppe Aresu, MD, Simon Duggan, FRCS, and \\ Gianni D. Angelini, FRCS
}

Objective: Off-pump coronary artery bypass grafting (OPCAB) is an established procedure in many cardiothoracic centers. For it to be widely applicable, however, teaching methods must be developed for surgical trainees. Early clinical outcomes and long-term survival of patients who underwent OPCAB at our institution by trainees supervised and unsupervised were compared with those of patients whose procedures were performed by senior surgeons. To evaluate evolution of training, outcomes were analyzed according to 3 different periods (1996-1999, 2000-2004, 2005-2009) and trainee seniority level.

\begin{abstract}
Methods: This was a retrospective, observational cohort study of prospectively collected data from 5566 consecutive patients who underwent isolated OPCAB performed by trainees $(1589,28.6 \% ; 1111$ supervised, 478 unsupervised) and by senior surgeons (3977, 71.4\%).

Results: Patients of senior surgeons were more likely to have left ventricular dysfunction $(P=.001)$, peripheral vascular disease $(P=.05)$, more extensive coronary artery disease $(P=.001)$, and higher EuroSCOREs than patients of trainees. In addition, trainees were less likely to have performed urgent operations $(P=.02)$ or reoperations $(P=.03)$ but more likely to have operated on patients with previous percutaneous coronary intervention $(P=.006)$. Early clinical outcomes and long-term survival were similar between groups and not related to trainee seniority, level of supervision by senior surgeon, or period during which training took place.
\end{abstract}

Conclusions: OPCAB is a safe and reproducible surgical technique that can be taught successfully to cardiothoracic trainees. Clinical outcomes are unrelated to level of supervision or seniority of trainees. (J Thorac Cardiovasc Surg 2012;143:1247-53)

Supplemental material is available online.

Residents in cardiothoracic surgery have recently been confronted with the need to gain experience in off-pump coronary artery bypass grafting (OPCAB) as an alternative approach to coronary revascularization. Senior cardiac surgeons are fully aware of the importance of training the next generation of surgeons, but at the same time they have an overriding responsibility to ensure patients' safety and good clinical outcomes. Various academic centers have evaluated the safety of training residents to perform cardiac surgery. ${ }^{1-7}$ Limited information, however, is available on the impact of training in OPCAB for an

\footnotetext{
From the Bristol Heart Institute, University of Bristol, Bristol, United Kingdom. Supported by the British Heart Foundation and the Bristol NIHR Biomedical Research Unit in Cardiovascular Medicine.

Disclosures: Authors have nothing to disclose with regard to commercial support. Received for publication Oct 28, 2010; revisions received Aug 29, 2011; accepted for publication Sept 26, 2011; available ahead of print Nov 4, 2011

Address for reprints: Gianni D. Angelini, FRCS, Bristol Heart Institute, Bristol BS2 8HW, United Kingdom (E-mail: G.D.Angelini@bristol.ac.uk). $0022-5223 / \$ 36.00$

Crown Copyright $\odot 2012$ Published by Elsevier Inc. on behalf of The American Association for Thoracic Surgery

doi:10.1016/j.jtcvs.2011.09.049
}

extended period and in particular on the effect of seniority level of trainees on clinical outcomes. At our institution, OPCAB has evolved rapidly in the last 14 years, and cardiothoracic trainees have been exposed to this new technique as an integral part of their surgical program. ${ }^{3,8-10}$ The purpose of this study was to compare the performances of trainees, supervised or unsupervised, with those of senior surgeons with respect to early clinical outcome and long-term survival in patients undergoing OP$\mathrm{CAB}$ operations. Finally, to evaluate the evolution of training, outcomes were then analyzed according to 3 different time periods (1996-1999, 2000-2004, 2005-2009) and the seniority level of trainees.

\section{MATERIALS AND METHODS \\ Data Collection}

The study was approved by the clinical audit committee of the University Hospitals Bristol Foundation Trust to meet ethical and legal requirements, and individual consent was waived. This was a retrospective, observational, cohort study of prospectively collected data from consecutive patients who underwent isolated OPCAB operations at the Bristol Heart Institute between April 1996 and November 2009. The data collection form was entered into a database (Patient Analysis \& Tracking System; Dendrite Clinical Systems, London, UK) and included 5 sections that were filled in consecutively by anesthetists, surgeons, and intensive care unit, highdependency unit, and ward nurses. The resulting base sample contained detailed clinical information on 5566 patients, of whom $3977(71.4 \%)$ were operated on by senior surgeons and $1589(28.6 \%)$ were operated on by 


\section{Abbreviation and Acronym \\ $\mathrm{OPCAB}=$ off-pump coronary artery bypass grafting}

cardiothoracic trainees (478 [30\%] unsupervised). Early clinical outcome and long-term survival were analyzed comparing the operations performed by trainees and senior surgeons. To evaluate the evolution of the training in $\mathrm{OPCAB}$, operations performed by trainees were divided into 3 subgroups according to the periods in which they were carried out (1996-1999, 2000-2004, 2005-2009). Finally, clinical outcomes were evaluated according to the seniority level of trainees in the UK specialist training program in cardiothoracic surgery or equivalent (Calman year 1-6).

\section{Training Program}

The Bristol Heart Institute is a regional cardiac surgical center and part of the UK national training program. The UK cardiothoracic training program is conducted over a 6-year period, and admission to it requires successful completion of a 2-year basic surgical training program. Two to three National Training Numbers were allocated to our unit at any time during the study period. In addition, 4 to 6 clinical research or service clinical fellows completed the surgical rota. Seniority level of trainees with official training numbers was defined according to year of training in the UK specialist program in cardiothoracic surgery (Calman year 1-6). For trainees who did not have an official UK training number (research or clinical fellows), the level of experience was retrospectively reviewed and assigned according to equivalent criteria.

\section{Definitions}

In-hospital mortality included all deaths within 30 days of operation, irrespective of where the death occurred, and all in-hospital deaths after 30 days among patients who had not been discharged after the index operation. Perioperative myocardial infarction, pacing, arrhythmias, and inotropic requirement were recorded and defined as previously reported elsewhere. ${ }^{11}$ Pulmonary complication included chest infection, ventilation failure, reintubation, and tracheostomy. Postoperative blood loss was defined as total chest tube drainage. Neurologic complications included permanent and transient strokes. Renal complications included acute renal failure, defined as the requirement of hemodialysis or an elevated creatinine level $(>200 \mathrm{mmol} / \mathrm{L})$. Infective complication included septicemia and sternal and leg wound infections, defined by positive culture and requirement for antibiotic therapy. ${ }^{11}$

The completeness of revascularization was identified by comparing the number of distal anastomoses with the number of diseased coronary systems observed on the preoperative angiogram. If the number of distal anastomosis performed equaled the total number of coronary systems with significant disease, the completeness of revascularization index was 1 . Patients who had more distal anastomoses performed than the number of vessels with angiographically significant diseases had a completeness of revascularization index greater than 1 and were classified as having a complete revascularization.

A supervised operation performed by a trainee was defined as one in which the senior surgeon was scrubbed in and acted as first assistant. An unsupervised operation was defined as one in which the trainees had reviewed the case and planned the surgical strategy with the senior surgeon who was not scrubbed in at the operating theater but was available, generally in his or her office.

\section{Patient Survival}

Patient records were linked to the National Strategic Tracing Service administrative mortality database, which records all the deaths in the United Kingdom. To establish current vital status, patients were matched against the National Strategic Tracing Service for patient name, National Health Service unique number, date of birth, and post code. Importantly, the cause of death was neither considered nor available in this study; thus the study compared all-cause mortality among the groups.

\section{Anesthetic and Surgical Technique}

Anesthetic technique consisted of propofol infusion at $3 \mathrm{mg} /(\mathrm{kg} \cdot \mathrm{h})$ combined with alfentanil hydrochloride (INN alfentanil) infusion at 0.5 to $1 \mu \mathrm{g} /(\mathrm{kg} \cdot \mathrm{min})$. Neuromuscular blockade was achieved by 0.1 to 0.15 $\mathrm{mg} / \mathrm{kg}$ pancuronium bromide or vecuronium, and the lungs were ventilated to normocapnia with air and oxygen (45\% to $50 \%)$. Heparin (100 IU/kg) was administered before the start of the first anastomosis to achieve an activated clotting time of 250 to 350 seconds. On completion of all anastomoses, protamine was given to reverse the effect of heparin and return the activated clotting time to preoperative levels.

The method of exposure to perform the anastomoses consisted of a technique that has been previously reported elsewhere. ${ }^{12}$ Stabilization was achieved with a reusable stainless steel stabilizer (Abbey Surgical Limited, Mitcham, UK) developed at our institution. Since the beginning of 1999, all anastomoses have been performed with an intracoronary shunt to ensure distal perfusion (Flothru Biovascular Inc, St Paul, Minn). Postoperative management was according to standard protocols as previously detailed elsewhere. ${ }^{13}$

\section{Statistical Analysis}

All statistical analysis was performed with SPSS statistical software (version 15.0; BM Corporation, Armonk, NY) and StatsDirect (version 2.7.2; StatsDirect Ltd, Cheshire, UK). Continuous data were expressed as mean $\pm \mathrm{SD}$, and categoric data were expressed as percentages. The Kolmogorov-Smirnov test was used to check for normality of data before further analysis. Differences between the groups were compared with the use of the Student $t$ test or with the analysis of variance where appropriate for continuous variables and with the $\chi^{2}$ test where appropriate for categoric variables. Nonparametric methods were used for variables that were not normally distributed. Stepwise multivariable regression analysis was used to identify independent risk factors for in-hospital mortality, with a significance level of .05 used for both entry and selection. Similarly, multivariable Cox proportional hazard modeling was used to identify independent risk factors for all-cause mortality. Covariates under consideration for all models were all baseline characteristics (as listed in Table 1), the grade of the first operator (senior surgeon and trainees), and the completeness of revascularization. Overall survival was estimated by using the Kaplan-Meier method and was expressed as a percentage. All reported $P$ values are 2-sided.

\section{RESULTS}

\section{Trainees Versus Senior Surgeons}

Between April 1996 and November 2009, a total of 5566 $\mathrm{OPCAB}$ procedures were performed at our institution, of which $3977(71.4 \%)$ were done by senior surgeons $(\mathrm{n}=9)$ and $1589(28.6 \%)$ were done by trainees $(\mathrm{n}=15$; Table 1). Of the operations performed by the trainees, 478 $(30 \%)$ were unsupervised. Preoperative patient characteristics are shown in Table 1 and were similar between groups with respect to sex, diabetes mellitus, chronic obstructive pulmonary disease, Canadian Cardiovascular Society class, left main stem stenosis, and intra-aortic balloon pump requirement. Trainees operated on patients with a significantly lower proportion of left ventricular dysfunction $(P=.001)$, lower proportion of peripheral vascular disease $(P=.05)$, less extensive coronary artery disease $(P=.001)$, and thus a lower EuroSCORE $(P=.001)$. In addition, trainees 
TABLE 1. Patient characteristics for operations performed by senior surgeons and by supervised and unsupervised trainees

\begin{tabular}{|c|c|c|c|c|}
\hline & $\begin{array}{c}\text { Senior surgeons } \\
\quad(\mathbf{n}=\mathbf{3 9 7 7}) \\
\end{array}$ & $\begin{array}{c}\text { Supervised trainees } \\
(\mathrm{n}=\mathbf{1 1 1 1})\end{array}$ & $\begin{array}{l}\text { Unsupervised trainees } \\
\qquad(n=478)\end{array}$ & $\begin{array}{c}P \\
\text { value } \\
\end{array}$ \\
\hline Age $(y$, mean $\pm S D)$ & $65.4 \pm 9$ & $64.6 \pm 9$ & $65.2 \pm 9$ & .03 \\
\hline Body mass index $\left(\mathrm{kg} / \mathrm{m}^{2}\right.$, mean $\left.\pm \mathrm{SD}\right)$ & $28.2 \pm 5.1$ & $27.9 \pm 4.8$ & $28 \pm 4.1$ & .3 \\
\hline Female (no.) & $749(18.8 \%)$ & $196(17.6 \%)$ & $97(20.3 \%)$ & .4 \\
\hline Canadian Cardiovascular Society class $($ mean $\pm \mathrm{SD})$ & $2.4 \pm 1.1$ & $2.4 \pm 1.1$ & $2.5 \pm 0.1$ & .3 \\
\hline New York Heart Association functional class (mean \pm SD) & $2 \pm 0.8$ & $2 \pm 0.7$ & $1.9 \pm 0.8$ & .01 \\
\hline Diabetes mellitus (no.) & $831(20.8 \%)$ & $214(19.3 \%)$ & $106(22.2 \%)$ & .3 \\
\hline Hypertension (no.) & $2814(70.8 \%)$ & $771(69.4 \%)$ & $326(68.2 \%)$ & .4 \\
\hline Cerebrovascular disease (no.) & $335(8.4 \%)$ & $78(7 \%)$ & $28(5.9 \%)$ & .06 \\
\hline Vascular disease (no.) & $405(10.2 \%)$ & $88(8 \%)$ & $43(9 \%)$ & .05 \\
\hline Chronic obstructive pulmonary disease (no.) & $427(10.7 \%)$ & $127(11.4 \%)$ & $54(11.3 \%)$ & .7 \\
\hline History of atrial fibrillation (no.) & $135(3.3 \%)$ & $33(3 \%)$ & $12(2.5 \%)$ & .5 \\
\hline Creatinine $(\mathrm{mmol} / \mathrm{L}$, mean $\pm \mathrm{SD})$ & $109 \pm 33$ & $110 \pm 36$ & $109 \pm 44$ & .5 \\
\hline Ejection fraction $<30 \%$ (no.) & $185(4.6 \%)$ & $26(2.3 \%)$ & $14(2.9 \%)$ & .001 \\
\hline Previous myocardial infarction (no.) & $1915(48.3 \%)$ & $511(46.2 \%)$ & $216(45.2 \%)$ & .2 \\
\hline Previous percutaneous coronary intervention (no.) & $253(6.3 \%)$ & $100(9 \%)$ & $28(5.9 \%)$ & .006 \\
\hline Reoperative surgery (no.) & $64(1.6 \%)$ & $7(0.6 \%)$ & $5(1 \%)$ & .03 \\
\hline Preoperative intra-aortic balloon pump use & $14(0.3 \%)$ & $3(0.3 \%)$ & $4(0.4 \%)$ & .8 \\
\hline Urgent operation (no.) & $1828(45.9 \%)$ & $461(41.5 \%)$ & $224(46.9 \%)$ & .02 \\
\hline EuroSCORE (no.) & $3.9 \pm 2.3$ & $3.5 \pm 2$ & $3.6 \pm 2$ & .001 \\
\hline Left main disease (no.) & $918(25.3 \%)$ & $240(21.6 \%)$ & $117(24.5 \%)$ & .4 \\
\hline Coronary artery disease (vessels, mean $\pm \mathrm{SD}$ ) & $2.5 \pm 0.6$ & $2.4 \pm 0.7$ & $2.3 \pm 0.7$ & .001 \\
\hline
\end{tabular}

were less likely to have performed urgent operations $(P=.02)$ or reoperative surgery $(P=.03)$; however, they did operate on more patients with previous percutaneous coronary intervention $(P=.006)$. Thirty patients in the senior surgeons group $(0.8 \%), 5$ patients in the supervised trainees group $(0.5 \%)$, and 2 patients $(0.4 \%)$ in the unsupervised group had to undergo conversion to conventional coronary artery bypass grafting with cardiopulmonary bypass for hemodynamic or electrical instability. Even though the group operated on by trainees received fewer coronary grafts and had a lower completeness of revascularization index, no difference was noted between the groups in the rate of completeness of revascularization $(P=.7)$.

Postoperative morbidity and mortality are shown in Table 2. In hospital-mortalities were $1.3 \%$ in the senior surgeons group, $1.2 \%$ in the supervised trainees group, and $0.8 \%$ in the unsupervised trainees group $(P=.7)$. The incidences of respiratory complications, neurologic complications, renal complications, inotropic use, and chest infection were similar among groups. Total blood loss, intubation time, and intensive care unit and hospital stays were similar among groups.

TABLE 2. Operative and postoperative results of operations performed by senior surgeons and by supervised and unsupervised trainees

\begin{tabular}{|c|c|c|c|c|}
\hline & $\begin{array}{l}\text { Senior surgeons } \\
\quad(\mathbf{n}=\mathbf{3 9 7 7})\end{array}$ & $\begin{array}{l}\text { Supervised trainees } \\
\quad(\mathbf{n}=1111)\end{array}$ & $\begin{array}{c}\text { Unsupervised trainees } \\
\quad(\mathbf{n}=\mathbf{4 7 8})\end{array}$ & $P$ value \\
\hline Distal anastomoses (mean $\pm \mathrm{SD}$ ) & $2.5 \pm 0.8$ & $2.4 \pm 0.7$ & $2.3 \pm 0.7$ & .001 \\
\hline Completeness of revascularization index (mean $\pm \mathrm{SD}$ ) & $1.03 \pm 0.23$ & $1.01 \pm 0.22$ & $1.02 \pm 0.27$ & .01 \\
\hline Complete revascularization (no.) & $3486(87.6 \%)$ & $981(88.3 \%)$ & $424(88.7 \%)$ & .7 \\
\hline Conversion to cardiopulmonary bypass (no.) & $30(0.8 \%)$ & $5(0.4 \%)$ & $2(0.3 \%)$ & .1 \\
\hline In-hospital mortality (no.) & $53(1.3 \%)$ & $13(1.2 \%)$ & $4(0.8 \%)$ & .7 \\
\hline Reoperation for bleeding (no.) & $71(1.7 \%)$ & $21(1.9 \%)$ & $14(2.9 \%)$ & .2 \\
\hline Blood loss $(\mathrm{mL}$, mean $\pm \mathrm{SD})$ & $784 \pm 457$ & $787 \pm 418$ & $825 \pm 477$ & .2 \\
\hline Perioperative myocardial infarction (no.) & $101(2.5 \%)$ & $37(3.2 \%)$ & $15(3.1 \%)$ & .4 \\
\hline Postoperative Inotropes (no.) & $1559(39.2 \%)$ & $453(40.8 \%)$ & $175(36.6 \%)$ & .3 \\
\hline Postoperative intra-aortic balloon pump (no.) & $88(2.2 \%)$ & $12(1 \%)$ & $9(1.7 \%)$ & .4 \\
\hline Stroke (no.) & $8(0.2 \%)$ & $5(0.5 \%)$ & $0(0 \%)$ & .1 \\
\hline Transient ischemic attack (no.) & $15(0.3 \%)$ & $2(0.2 \%)$ & $0(0 \%)$ & .2 \\
\hline Renal complications (no.) & $280(7 \%)$ & $68(6.1 \%)$ & $37(7.7 \%)$ & .4 \\
\hline Pulmonary complications (no.) & $481(12 \%)$ & $142(12.8 \%)$ & $63(13.2 \%)$ & .7 \\
\hline Intensive care unit stay $(\mathrm{d}$, mean $\pm \mathrm{SD})$ & $1.6 \pm 3.6$ & $1.5 \pm 2.7$ & $1.5 \pm 2.2$ & .5 \\
\hline Hospital stay $(\mathrm{d}$, mean $\pm \mathrm{SD})$ & $7.7 \pm 6.5$ & $7.9 \pm 6.5$ & $7.7 \pm 5.3$ & .8 \\
\hline
\end{tabular}




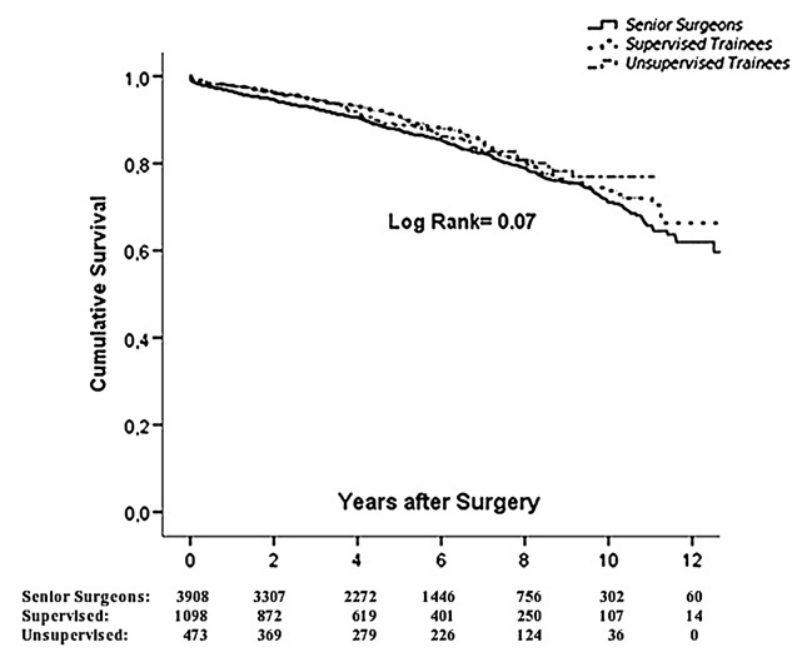

FIGURE 1. Kaplan-Meier survival curves for operations performer by senior surgeons, supervised trainees, and unsupervised trainees.

In multivariate analysis with logistic regression modeling, trainee as operator (supervised or unsupervised) was not independently associated with in-hospital mortality (odds ratio, $0.73 ; 95 \%$ confidence interval, $0.4-1.3 ; P=.3$ ).

Of the 5566 patients undergoing OPCAB operations, 5496 patients were discharged alive $(98.5 \%)$. Among these, $5396(98.7 \%)$ were successfully linked to the National Strategic Tracing Service administrative mortality database and were included in the longitudinal analyses (3899 senior surgeons and 1470 trainees performed these cases). Median follow-up was $5.1 \pm 3.2$ years for the senior surgeons, 5 \pm 3.1 years for the supervised trainees group, and $5.2 \pm$ 3.1 for the unsupervised trainees group $(P=.3)$. There were 782 late deaths during the study period $(14.5 \%)$. The Kaplan-Meier event-free survival curves (Figure 1) show no significant difference between the groups at 1, 5, and 10 years: senior surgeons had event-free survivals of $96.5 \%, 87.9 \%$, and $71.9 \%$, respectively; supervised trainees had event-free survivals of $97.8 \%, 90.6 \%$, and $73.7 \%$; and unsupervised trainees had event-free survivals of $97.9 \%, 88.8 \%$, and $76.9 \%$ (log-rank $P=.07$ ).

In the multivariate Cox proportional hazards model, trainee as operator was not associated with long-term survival (hazard ratio, 1.034; 95\% confidence interval, $0.867-1.232 ; P=.712$ ). The variables that emerged as independent predictors of late death are shown in Table E1.

\section{Time Period Analysis}

The operations performed by trainees during the 3 chosen time periods increased progressively and were 128 (19961999), 626 (2000-2004), and 835 (2005-2009; Figure 2). Preoperative characteristics are reported by time period in Table 3. We observed a significant increase in the number of unsupervised operation performed by trainees $(P=.001)$, as well as a significant change in the preoperative

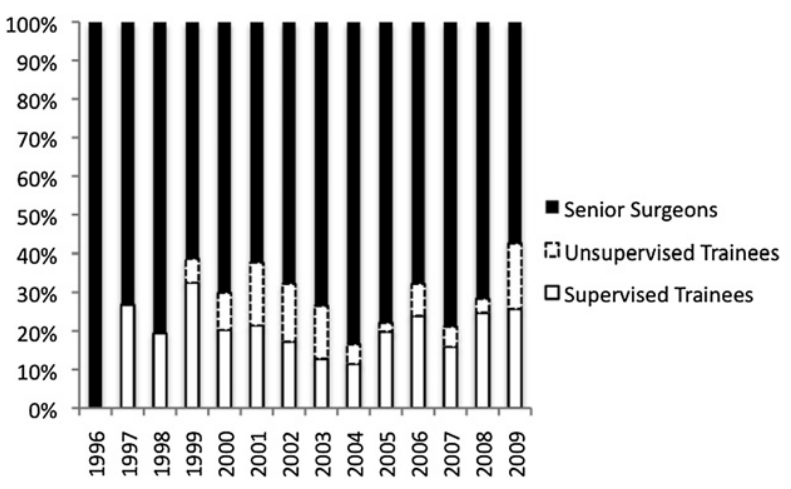

FIGURE 2. Breakdown of off-pump coronary artery bypass grafting operations performer by senior surgeons, supervised trainees, and unsupervised trainees (1996-2009).

risk profile of the patients operated on by trainees, with increases in mean age $(P=.001)$, New York Heart Association class $(P=.001)$, prevalence of diabetes $(P=.007)$, prevalence of previous percutaneous coronary intervention $(P=.001)$, EuroSCORE $(P<.001)$, and extent of coronary artery disease $(P=.001)$. There was also a significant progressive increase in the mean number of grafts per patient $(P=.001)$. Postoperative mortality and morbidity, however, remained similar during the study period (Table 4).

\section{Seniority Level of Trainees}

The number of operations performed and the preoperative characteristics of patients operated on by trainees according to their seniority (Calman year) are reported in Table E2. No significant differences were noted in term of preoperative characteristics of the patients. Clinical outcomes are shown in Table 5. In-hospital mortality ranged from $0 \%$ (year 1 ) to $2.8 \%$ (year $3 ; P=.751$ ). The incidences of respiratory, cardiac, neurologic, pulmonary and renal complications and the duration of hospital stay remained similar across all the Calman year groups.

\section{DISCUSSION}

This study summarizes a 14-year experience at a single institution in training cardiothoracic residents to perform OPCAB procedures. There are 2 main findings. (1) Multivessel $\mathrm{OPCAB}$ is a safe and reproducible technique that can be taught successfully to cardiothoracic surgical trainees. (2) Early clinical outcomes and long-term survival were not related to the trainee's seniority, the level of senior surgeon supervision, or the different time periods of development of OPCAB at our institution.

The rapid evolution of OPCAB in recent years has resulted in its widespread popularization as an alternative to conventional coronary artery bypass grafting with cardiopulmonary bypass. Residents in cardiothoracic surgery have been confronted with the need to gain experience in this novel approach to myocardial revascularization. ${ }^{14}$ 
TABLE 3. Patient characteristics for operations by trainees broken down by time period

\begin{tabular}{|c|c|c|c|c|}
\hline & $1996-1999(n=128)$ & $2000-2004(n=626)$ & $2005-2009(n=835)$ & $P$ value \\
\hline Age $(y$, mean $\pm S D)$ & $62.5 \pm 9.7$ & $63.8 \pm 9.2$ & $65.8 \pm 9.4$ & .001 \\
\hline Body mass index $\left(\mathrm{kg} / \mathrm{m}^{2}\right.$, mean $\left.\pm \mathrm{SD}\right)$ & $28.1 \pm 4$ & $27.8 \pm 4$ & $28 \pm 5$ & .536 \\
\hline Female (no.) & $29(22.6 \%)$ & $120(19.1 \%)$ & $144(82.7 \%)$ & .282 \\
\hline Canadian Cardiovascular Society class (mean \pm SD) & $2.9 \pm 0.8$ & $2.6 \pm 1$ & $2.2 \pm 1$ & .001 \\
\hline New York Heart Association class (mean \pm SD) & $1.9 \pm 0.7$ & $2.1 \pm 0.8$ & $2.2 \pm 0.8$ & .001 \\
\hline Diabetes (no.) & $18(14 \%)$ & $110(17.5 \%)$ & $192(22.9 \%)$ & .007 \\
\hline Hypertension (no.) & $68(53.1 \%)$ & $391(62.5 \%)$ & $638(76.4 \%)$ & .01 \\
\hline Cerebrovascular disease (no.) & $7(5.5 \%)$ & $30(4.8 \%)$ & $69(8.3 \%)$ & .02 \\
\hline Vascular disease (no.) & $12(9.4 \%)$ & $54(8.6 \%)$ & $65(7.8 \%)$ & .7 \\
\hline Chronic obstructive pulmonary disease (no.) & $14(10.9 \%)$ & $87(13.9 \%)$ & $80(9.6 \%)$ & .03 \\
\hline History of atrial fibrillation (no.) & $2(1.6 \%)$ & $14(2.2 \%)$ & $29(3.5 \%)$ & .2 \\
\hline Creatinine $(\mathrm{mmol} / \mathrm{L}$, mean $\pm \mathrm{SD})$ & $110 \pm 26$ & $113 \pm 49$ & $107 \pm 29$ & .01 \\
\hline Ejection fraction $<30 \%$ & $8(6.2 \%)$ & $19(3 \%)$ & $13(1.5 \%)$ & .003 \\
\hline Previous myocardial infarction (no.) & $63(49.2 \%)$ & $282(45 \%)$ & $382(45.7 \%)$ & .643 \\
\hline Previous percutaneous coronary intervention (no.) & $5(3.9 \%)$ & $29(4.6 \%)$ & $94(11.2 \%)$ & .001 \\
\hline Reoperative surgery (no.) & $2(1.6 \%)$ & $9(1.4 \%)$ & $1(0.1 \%)$ & .009 \\
\hline Preoperative intra-aortic balloon pump (no.) & $4(3.1 \%)$ & $1(0.2 \%)$ & $0(0 \%)$ & .001 \\
\hline Urgent operation (no.) & $55(42.9 \%)$ & $262(41.8 \%)$ & $368(44 \%)$ & .721 \\
\hline EuroSCORE $($ mean $\pm \mathrm{SD})$ & $2.2 \pm 1.5$ & $3.4 \pm 2$ & $3.6 \pm 2$ & .0004 \\
\hline Left main disease (no.) & $21(16.4 \%)$ & $112(17.9 \%)$ & $224(26.8 \%)$ & .001 \\
\hline Coronary artery disease (vessels, mean \pm SD) & $2.2 \pm 0.7$ & $2.3 \pm 0.7$ & $2.5 \pm 0.7$ & .001 \\
\hline
\end{tabular}

Senior surgeons therefore face a dilemma that pits their duty to deliver the highest possible standard of care to their patients against their duty to teach OPCAB to trainees. Studies such as this and others are important to audit trainee performance and to reassure patients that good clinical outcomes are being achieved. Importantly, we are able to show similar early clinical outcomes and long-term survival for patients operated on by trainees, supervised and unsupervised, and by senior surgeons. This is possibly a reflection of the careful patients selection by senior surgeons in allocating cases to be operated on by trainees.

In 2000, a survey from several cardiothoracic training centers in the United States demonstrated that only 22\% of residents had performed 20 or more OPCAB procedures during their training, and only $12 \%$ had performed 20 or more complete myocardial revascularizations with $\mathrm{OPCAB}$ techniques. ${ }^{15}$ We have previously reported our early experience in teaching OPCAB, with no difference in clinical outcome when the surgery was performed by senior surgeons or cardiothoracic trainees. ${ }^{3,8-10} \mathrm{We}$ have also provided evidence in the early phase of our program with 4 trainees and the senior surgeon who developed the OPCAB technique at our institution (G.D.A.) that performance monitoring is practical with control charts (eg, cumulative sum charts) and that teaching OPCAB in a residency program is effective, with an average failure rate for

TABLE 4. Postoperative outcomes of patients operated on by trainees broken down by time period

\begin{tabular}{|c|c|c|c|c|}
\hline & $1996-1999(n=128)$ & $2000-2004(n=626)$ & $2005-2009(n=835)$ & $P$ value \\
\hline Distal anastomoses (mean $\pm \mathrm{SD}$ ) & $2.1 \pm 0.8$ & $2.3 \pm 0.7$ & $2.5 \pm 0.7$ & .001 \\
\hline Completeness of revascularization index (mean $\pm \mathrm{SD})$ & $0.7 \pm 0.4$ & $0.9 \pm 0.3$ & $0.9 \pm 0.3$ & .003 \\
\hline Complete revascularization (no.) & $102(79.6 \%)$ & $565(90.2 \%)$ & $738(88.3 \%)$ & .003 \\
\hline Unsupervised operation (no.) & $13(3.3 \%)$ & $259(53.8 \%)$ & $206(43.9 \%)$ & .001 \\
\hline Conversion to cardiopulmonary bypass (no.) & $0(0 \%)$ & $2(0.3 \%)$ & $5(0.6 \%)$ & .5 \\
\hline In-hospital mortality (no.) & $1(0.8 \%)$ & $9(1.4 \%)$ & $7(0.8 \%)$ & .51 \\
\hline Reoperation for bleeding (no.) & $5(3.9 \%)$ & $11(1.8 \%)$ & $19(2.3 \%)$ & .3 \\
\hline Postoperative myocardial infarction (no.) & $3(2.3 \%)$ & $18(2.8 \%)$ & $30(3.5 \%)$ & 6 \\
\hline Postoperative Inotropes (no.) & $50(39 \%)$ & $234(37.3 \%)$ & $344(41.1 \%)$ & .333 \\
\hline Postoperative intra-aortic balloon pump (no.) & $2(1.5 \%)$ & $13(2 \%)$ & $6(0.7 \%)$ & .077 \\
\hline Stroke (no.) & $0(0 \%)$ & $4(0.6 \%)$ & $4(0.5 \%)$ & .6 \\
\hline Transient ischemic attack (no.) & $0(0 \%)$ & $1(0.1 \%)$ & $1(0.1 \%)$ & .895 \\
\hline Renal complications (no.) & $10(7.8 \%)$ & $46(7.3 \%)$ & $49(5.8 \%)$ & .032 \\
\hline Pulmonary complications (no.) & $21(16.4 \%)$ & $81(12.9 \%)$ & $103(12.3 \%)$ & .44 \\
\hline Intensive care unit stay $(\mathrm{d}$, mean $\pm \mathrm{SD}$ ) & $1.3 \pm 1.0$ & $1.7 \pm 4.2$ & $1.4 \pm 1.3$ & .06 \\
\hline Hospital stay (d, mean \pm SD) & $8 \pm 6$ & $8 \pm 6$ & $7 \pm 5$ & .835 \\
\hline
\end{tabular}


TABLE 5. Postoperative outcomes of patients operated on by trainees broken down by trainee seniority (Calman year)

\begin{tabular}{|c|c|c|c|c|c|c|c|}
\hline & $\begin{array}{c}\text { Year 1 } \\
(n=18)\end{array}$ & $\begin{array}{c}\text { Year } 2 \\
(\mathbf{n}=155)\end{array}$ & $\begin{array}{c}\text { Year 3 } \\
(\mathbf{n}=\mathbf{2 4 7})\end{array}$ & $\begin{array}{c}\text { Year } 4 \\
(n=386)\end{array}$ & $\begin{array}{c}\text { Year } 5 \\
(\mathbf{n}=\mathbf{2 8 7})\end{array}$ & $\begin{array}{c}\text { Year } 6 \\
(n=496)\end{array}$ & $\begin{array}{c}P \\
\text { value }\end{array}$ \\
\hline Distal anastomoses (mean $\pm \mathrm{SD}$ ) & $2.0 \pm 0.7$ & $2.3 \pm 0.7$ & $2.4 \pm 0.7$ & $2.5 \pm 0.7$ & $2.4 \pm 0.7$ & $2.4 \pm 0.7$ & .341 \\
\hline Completeness of revascularization index (mean $\pm \mathrm{SD})$ & $0.91 \pm 0.2$ & $0.99 \pm 0.2$ & $1.0 \pm 0.2$ & $1.0 \pm 0.2$ & $1.0 \pm 0.2$ & $1.0 \pm 0.2$ & .6 \\
\hline Complete revascularization (no.) & $15(83.3 \%)$ & $138(89 \%)$ & $226(91.5 \%)$ & $356(92.2 \%)$ & $246(85.7 \%)$ & $424(85.5 \%)$ & .01 \\
\hline Conversion to cardiopulmonary bypass (no.) & $0(0 \%)$ & $2(1.3 \%)$ & $2(0.8 \%)$ & $2(0.5 \%)$ & $1(0.4 \%)$ & $0(0 \%)$ & .5 \\
\hline In-hospital mortality (no.) & $0(0 \%)$ & $2(1.2 \%)$ & $3(1.2 \%)$ & $2(0.5 \%)$ & $5(1.7 \%)$ & $5(1 \%)$ & .751 \\
\hline Reoperation for bleeding (no.) & $0(0 \%)$ & $7(4.5 \%)$ & $6(2.4 \%)$ & $15(3.8 \%)$ & $16(5.5 \%)$ & $17(3.4 \%)$ & .439 \\
\hline Perioperative myocardial infarction (no.) & $1(5.5 \%)$ & $2(1.2 \%)$ & $12(4.8 \%)$ & $17(4.4 \%)$ & $6(2 \%)$ & $13(2.6 \%)$ & .167 \\
\hline Postoperative inotropes (no.) & $7(38.8 \%)$ & $56(36.1 \%)$ & $104(42.1 \%)$ & $158(40.9 \%)$ & $110(38.3 \%)$ & $193(38.9 \%)$ & .847 \\
\hline Postoperative intra-aortic balloon pump (no.) & $0(0 \%)$ & $1(0.6 \%)$ & $7(2.8 \%)$ & $5(1.3 \%)$ & $3(1 \%)$ & $5(1 \%)$ & .340 \\
\hline Stroke (no.) & $0(0 \%)$ & $0(0 \%)$ & $1(0.4 \%)$ & $3(0.7 \%)$ & $0(0 \%)$ & $1(0.2 \%)$ & .5 \\
\hline Transient ischemic attack (no.) & $0(0 \%)$ & $0(0 \%)$ & $0(0 \%)$ & $1(0.2 \%)$ & $1(0.3 \%)$ & $0(0 \%)$ & .726 \\
\hline Renal complications (no.) & $0(0 \%)$ & $11(7 \%)$ & $22(9 \%)$ & $22(5.6 \%)$ & $18(6.2 \%)$ & $32(6.4 \%)$ & .544 \\
\hline Pulmonary complications (no.) & $2(11.1 \%)$ & $19(12.2 \%)$ & $30(12.1 \%)$ & $46(11.9 \%)$ & $40(13.9 \%)$ & $68(13.7 \%)$ & .951 \\
\hline Intensive care unit stay $(\mathrm{d}$, mean $\pm \mathrm{SD})$ & $1.2 \pm 0.5$ & $1.9 \pm 0.4$ & $2.1 \pm 5.8$ & $1.4 \pm 1.6$ & $1.4 \pm 1.3$ & $1.3 \pm 0.9$ & .01 \\
\hline Hospital stay $(\mathrm{d}$, mean $\pm \mathrm{SD})$ & $10.7 \pm 6.6$ & $10.7 \pm 9$ & $11.5 \pm 13$ & $10.5 \pm 7.7$ & $9.2 \pm 5$ & $10.7 \pm 8.2$ & .408 \\
\hline
\end{tabular}

OPCAB after adjustment for case mix similar to or better than that for conventional on-pump coronary artery bypass grafting. ${ }^{9}$ During the past 14 years, the number of OPCAB operations performed at our institution has increased significantly, and at the same time, more of these procedures have been undertaken by an increasing number of trainees. The complexity of cases performed by trainees has gradually increased, as has the mean number of grafts per patient, without any increase in procedural morbidity and mortality. At the same time, there has been a significant increase in the number of OPCAB procedures performed without direct supervision, when the consultant was not scrubbed in with the trainee in the operating theater.

The study has several limitations that are important to consider when interpreting the main findings. It is necessarily observational, for both logistic and ethical reasons. The way in which cases were selected by senior surgeons for trainees is unlikely to be adequately characterized by our data, despite the large number of clinical variables available. Patients operated on by senior surgeons were more likely to have higher risks factors, possibly a reflection of the careful selection process when allocating cases to trainees. One important variable was not documented in the database, namely a shift from trainee to senior surgeon designation as main operator. A change in the designation of trainee to senior surgeon in cases of unexpected findings or intraoperative complications would have led to the performance of trainees being overestimated. We do not believe that this occurred to a significant extent; however, during the early stages of training, the senior surgeons may have intervened in an unplanned manner to perform 1 or more difficult anastomoses or to show the trainee how optimally to position and stabilize the heart. One of the often reported major drawbacks of OPCAB is that the early in-hospital benefits are achieved at the expense of recurrence of angina symptoms and an increased need for revascularization. We have recently provided evidence in our 7 to 8 years of follow-up of the 2 BHACAS (Beating Heart Against Cardioplegic Arrest Studies) trials of similar graft patency: $89.4 \%$ and $89.0 \%$ in the on-pump and off-pump groups, respectively, with no difference in cardiac-related events or quality of life. ${ }^{16,17}$ We have not analyzed our data, however, to determine whether OPCAB procedures performed by residents resulted in a higher incidence of recurrent angina or the need for repeated revascularization in these patients. Lack of information on cardiac-related events and the need for repeated revascularization between procedures performed by residents and attending surgeons is a major limitation of this study. Although a resident's experience has not been shown to be associated with adverse outcomes of operations performed in other surgical subspecialties, such as general and eye surgery, ${ }^{18,19}$ the impact of a cardiothoracic trainee's seniority levels in cardiac surgery has seldom been investigated. ${ }^{20}$ In a recently published article, Bakaeen and collegues ${ }^{21}$ showed that a resident's level of experience does not influence early and midterm outcomes of on-pump coronary artery bypass grafting, although there was a significant association between lower level of experience and higher cardiopulmonary bypass and crossclamp times.

Cardiothoracic surgical training programs vary greatly in content depending on the particular institution, the interests of its staff referral, and the characteristics of the patients. In the United Kingdom, the training in cardiothoracic surgery spans 6 years, with no specific recommendations for OPCAB. In our institution, trainees are exposed to beatingheart coronary operations from the first year of their training program and start performing conventional coronary artery bypass grafting with cardiopulmonary bypass and OPCAB at the same time. After they have assisted senior surgeons for 40 to $50 \mathrm{OPCAB}$ procedures, trainees are started on simple off-pump cases, requiring only left anterior descending coronary artery or diagonal grafts, before gradually moving 
to posterior descending coronary artery grafting. This allows trainees to become progressively acclimated to various techniques of exposure, stabilization, and positioning of shunts before attempting to graft the circumflex system, which remains technically more challenging. By the end of the third year, trainees have performed between 30 and 40 cases as first operator under direct supervision, and proficiency is usually obtained after 80 to 100 OPCAB operations. ${ }^{3,9}$ During this phase, the senior surgeon assesses the level of progression of the individual trainees, because this may vary. This assessment is very much based on the surgeon's judgment, because the simple number of 40 and 80 cases as base for the first stage of training cannot for obvious reason be the only criteria. Every case is considered suitable for training, taking in consideration what has been explained here. Indeed, we have previously reported ${ }^{10}$ our experience of trainees operating on high-risk patients, with very few exception such as those with severely impaired left ventricular function or hemodynamic instability. In the last 2 years of training, with the exact timing at the discretion of the supervising surgeon's judgment that a particular trainee has reached a competent level, the trainees are allowed to performed unsupervised operations. The trainee discusses the case and surgical strategy with the senior surgeon, who is generally available in his or her office but not scrubbed in at the operating theater. Trainees rotate on a 6-month period with an individual senior surgeon (all the surgeons performing $\mathrm{OPCAB}$ procedures take part in the training program), and although the OPCAB surgical technique is very much standardized across the unit, they are still exposed to and benefit from seeing different surgical approaches.

In the current era of myocardial revascularization, it is essential to expose trainees to OPCAB techniques, which are an integral part of modern coronary surgery. We believe that at present, OPCAB training programs should be limited to institutions that perform large number of these operations per year, with senior surgeons proficient in using the technique. Our primary aim is to encourage the evolution of OPCAB but at the same time maintain a high standard of care. Furthermore, we strive to provide scientific evidence for changes in the training curriculum to transfer our experience to more and more young cardiothoracic surgeons. The future of OPCAB remains bright and expansive. OPCAB is a technique for the many and not the few, both surgeons and patients, but only with structured training and supervision in the right environment. ${ }^{22}$

\section{CONCLUSIONS}

Multivessel OPCAB is a safe and reproducible surgical technique that can be taught successfully to cardiothoracic surgical trainees. Early clinical outcomes and long-term survival are not related to the trainee's seniority or the level of supervision by the senior surgeons.

\section{References}

1. Baskett RJ, Buth KJ, Legaré JF, Hassan A, Hancock Friesen C, Hirsch GM, et al Is it safe to train residents to perform cardiac surgery? Ann Thorac Surg. 2002;74: 1043-8.

2. Sethi GK, Hammermeister KE, Oprian C, Henderson W. Impact of resident training on postoperative morbidity in patients undergoing single valve replacement. Department of Veterans Affairs Cooperative Study on Valvular Heart Disease. J Thorac Cardiovasc Surg. 1991;101:1053-9.

3. Caputo M, Chamberlain MH, Ozalp F, Underwood MJ, Ciulli F, Angelini GD Off-pump coronary operations can be safely taught to cardiothoracic trainees. Ann Thorac Surg. 2001;71:1215-9.

4. Goodwin AT, Birdi I, Ramesh TP, Taylor GJ, Nashef SA, Dunning JJ, et al. Effect of surgical training on outcome and hospital costs in coronary surgery. Heart 2001;85:454-7.

5. Yap CH, Andrianopoulos N, Dinh TD, Billah B, Rosalion A, Smith JA, et al. Short- and midterm outcomes of coronary artery bypass surgery performed by surgeons in training. J Thorac Cardiovasc Surg. 2009;137:1088-92.

6. Stoica SC, Kalavrouziotis D, Martin BJ, Buth KJ, Hirsch GM, Sullivan JA, et al. Long-term results of heart operations performed by surgeons-in-training. Circulation. 2008;30(14 Suppl):118:S1-6.

7. Asimakopoulos G, Karagounis AP, Valencia O, Rose D, Niranjan G, Chandrasekaran V. How safe is it to train residents to perform off-pump coronary artery bypass surgery? Ann Thorac Surg. 2006;81:568-72.

8. Caputo M, Bryan AJ, Capoun R, Mahesh B, Ciulli F, Hutter J, et al. The evolution of training in off-pump coronary surgery in a single institution. Ann Thorac Surg. 2002; 74:S1403-7.

9. Caputo M, Reeves BC, Rogers CA, Ascione R, Angelini GD. Monitoring the performance of residents during training in off-pump coronary surgery. $J$ Thorac Cardiovasc Surg. 2004;128:907-15

10. Ascione R, Reeves BC, Pano M, Angelini GD. Trainees operating on high-risk patients without cardiopulmonary bypass: a high-risk strategy? Ann Thorac Surg. 2004;78:26-33.

11. Yeatman M, Caputo M, Ascione R, Ciulli F, Angelini GD. Off-pump coronary artery bypass surgery for critical left main stem disease: safety, efficacy and outcome. Eur J Cardiothorac Surg. 2001;19:239-44.

12. Watters MP, Ascione R, Ryder IG, Ciulli F, Pitsis AA, Angelini GD. Haemodynamic changes during beating heart coronary surgery with the 'Bristol Technique'. Eur J Cardiothorac Surg. 2001;19:34-40.

13. Ascione R, Caputo M, Calori G, Lloyd CT, Underwood MJ, Angelini GD Predictors of atrial fibrillation after conventional and beating heart coronary surgery: a prospective, randomised study. Circulation. 2000;102 1530-5.

14. Murphy GJ, Rogers A, Caputo M, Angelini GD. Acquiring proficiency in offpump surgery: traversing the learning curve, reproducibility, and quality control. Ann Thorac Surg. 2005;80:1965-70.

15. Ricci M, Karamanoukian HL, D'Ancona G, DeLaRosa J, Karamanoukian RL, Choi S, et al. Survey of resident training in beating heart operations. Ann Thorac Surg. 2000;70:479-82.

16. Angelini GD, Taylor FC, Reeves BC, Ascione R. Early and midterm outcome af ter off-pump and on-pump surgery in Beating Heart Against Cardioplegic Arrest Studies (BHACAS 1 and 2): a pooled analysis of two randomised controlled trials. Lancet. 2002;359:1194-9.

17. Angelini GD, Culliford L, Smith DK, Hamilton MC, Murphy GJ, Ascione R, et al. Effects of on- and off-pump coronary artery surgery on graft patency, survival and health-related quality of life: long-term follow-up of 2 randomized controlled trials. J Thorac Cardiovasc Surg. 2009;137:295-303.

18. Crouch ER Jr. A comparison of the success rates of resident and attending strabismus surgery: discussion. J Pediatr Ophthalmol Strabismus. 1993;30: 157-8.

19. Shabtai M, Rosin D, Zmora O, Munz Y, Scarlat A, Shabtai EL, et al. The impact of a resident's seniority on operative time and length of hospital stay for laparoscopic appendectomy: outcomes used to measure the resident's laparoscopic skills. Surg Endosc. 2004;18:1328-30.

20. Guo LR, Chu MW, Tong MZ, Fox S, Myers ML, Kiaii B, et al. Does the trainee's level of experience impact on patient safety and clinical outcomes in coronary artery bypass surgery? J Card Surg. 2008;23:1-5.

21. Bakaeen FG, Dhaliwal AS, Chu D, Bozkurt B, Tsai P, LeMaire SA, et al. Does the level of experience of residents affect outcomes of coronary artery bypass surgery? Ann Thorac Surg. 2009;87:1127-34.

22. Patel NN, Angelini GD. Off-pump coronary artery bypass grafting: for the many or the few? J Thorac Cardiovasc Surg. 2010;140:951-3.e1. 
TABLE E1. Multivariate Cox proportional hazards model for independent predictors of long-term mortality

\begin{tabular}{lccc}
\hline \multicolumn{1}{c}{ Variable } & HR & \multicolumn{1}{c}{$\mathbf{9 5 \%}$ CI } & $\begin{array}{c}\boldsymbol{P} \\
\text { value }\end{array}$ \\
\hline Age (y) & 1.046 & $1.034-1.058$ & .001 \\
Preoperative New York Heart & 1.184 & $1.070-1.310$ & .001 \\
$\quad$ Association class & & & \\
Diabetes & 1.700 & $1.439-2007$ & .001 \\
Chronic obstructive pulmonary disease & 1.499 & $1.228-1.829$ & .001 \\
Vascular disease & 1.659 & $1.354-2.031$ & .001 \\
History of atrial fibrillation & 1.733 & $1.296-2.17$ & .001 \\
EuroSCORE & 1.066 & $1.025-1.208$ & .001 \\
Incomplete revascularization & 1.279 & $1.049-1.560$ & .015 \\
Trainee operator & 1.034 & $0.867-1.232$ & .712 \\
\hline
\end{tabular}

$H R$, Hazard ratio; $C I$, confidence interval.

TABLE E2. Characteristics of patients operated on by trainees broken down by seniority (Calman year)

\begin{tabular}{|c|c|c|c|c|c|c|c|}
\hline & $\begin{array}{c}\text { Year } 1 \\
(n=18)\end{array}$ & $\begin{array}{c}\text { Year } 2 \\
(\mathrm{n}=155)\end{array}$ & $\begin{array}{c}\text { Year } 3 \\
(n=247)\end{array}$ & $\begin{array}{c}\text { Year } 4 \\
(n=386)\end{array}$ & $\begin{array}{c}\text { Year } 5 \\
(\mathrm{n}=\mathbf{2 8 7})\end{array}$ & $\begin{array}{c}\text { Year } 6 \\
(n=496)\end{array}$ & $\begin{array}{c}P \\
\text { value } \\
\end{array}$ \\
\hline Age $(y$, mean $\pm S D)$ & $67.7 \pm 7.6$ & $66.1 \pm 8.3$ & $65.8 \pm 9.5$ & $67.6 \pm 8.3$ & $66.7 \pm 8.1$ & $66.7 \pm 9$ & .314 \\
\hline Body mass index $\left(\mathrm{kg} / \mathrm{m}^{2}\right.$, mean $\left.\pm \mathrm{SD}\right)$ & $26.6 \pm 3.4$ & $28.2 \pm 4.7$ & $28 \pm 4.2$ & $27.9 \pm 4.4$ & $27.9 \pm 4.2$ & $28.1 \pm 4$ & .917 \\
\hline Female (no.) & $4(22.2 \%)$ & $36(23 \%)$ & $39(15.7 \%)$ & $62(16 \%)$ & $53(18.4 \%)$ & $99(19.9 \%)$ & .316 \\
\hline Canadian Cardiovascular Society class (mean $\pm \mathrm{SD}$ & $2.07 \pm 0.9$ & $2.1 \pm 0.7$ & $2.1 \pm 0.8$ & $1.9 \pm 0.8$ & $2 \pm 0.7$ & $2 \pm 0.8$ & .614 \\
\hline Diabetes (no.) & $3(16.6 \%)$ & $29(18.7 \%)$ & $43(17.4 \%)$ & $85(22 \%)$ & $57(19.8 \%)$ & $103(20.7 \%)$ & .782 \\
\hline New York Heart Association class (no.) & $2 \pm 0.9$ & $2.1 \pm 0.7$ & $2.1 \pm 0.8$ & $1.9 \pm 0.8$ & $2 \pm 0.7$ & $2 \pm 0.8$ & .238 \\
\hline Hypertension (no.) & $12(66.7 \%)$ & $102(65.8 \%)$ & $163(66 \%)$ & $276(61.5 \%)$ & $196(68.3 \%)$ & $348(70.2 \%)$ & .6 \\
\hline Cerebrovascular disease (no.) & $2(11.1 \%)$ & $9(5.8 \%)$ & $11(4.5 \%)$ & $33(8.5 \%)$ & $15(5.2 \%)$ & $36(7.3 \%)$ & .3 \\
\hline Vascular disease (no.) & $1(5.5 \%)$ & $10(6.5 \%)$ & $23(9.3 \%)$ & $36(9.3 \%)$ & $20(7 \%)$ & $41(8.2 \%)$ & .798 \\
\hline Chronic obstructive pulmonary disease (no.) & $2(11.1 \%)$ & $20(12.9 \%)$ & $27(10.9 \%)$ & $38(9.8 \%)$ & $41(14.2 \%)$ & $53(10.6 \%)$ & .557 \\
\hline History of atrial fibrillation (no.) & $1(5.5 \%)$ & $4(2.5 \%)$ & $5(2 \%)$ & $17(4.4 \%)$ & $9(3 \%)$ & $9(1.8 \%)$ & .257 \\
\hline Creatinine $(\mathrm{mmol} / \mathrm{L}$, mean $\pm \mathrm{SD})$ & $109 \pm 24$ & $109 \pm 51$ & $117 \pm 41$ & $112 \pm 52$ & $106 \pm 22$ & $109 \pm 39$ & .105 \\
\hline Ejection fraction $<30 \%$ (no.) & $0(0 \%)$ & $2(1.29 \%)$ & $5(2 \%)$ & $9(2.33 \%)$ & $8(2.7 \%)$ & $16(3.2 \%)$ & .7 \\
\hline Previous myocardial infarction (no.) & $7(38.9 \%)$ & $70(45.2 \%)$ & $111(44.9 \%)$ & $169(44.1 \%)$ & $137(47.9 \%)$ & $233(47 \%)$ & .9 \\
\hline Previous percutaneous coronary intervention (no.) & $3(16.6 \%)$ & $11(7 \%)$ & $19(7.6 \%)$ & $33(8.5 \%)$ & $24(8.3 \%)$ & $38(7.6 \%)$ & .8 \\
\hline Reoperative surgery (no.) & $1(5.6 \%)$ & $0(0 \%)$ & $4(1.6 \%)$ & $4(1 \%)$ & $1(0.3 \%)$ & $1(0.4 \%)$ & .05 \\
\hline Preoperative intra-aortic balloon pump (no.) & $0(0 \%)$ & $0(0 \%)$ & $0(0 \%)$ & $1(0.3 \%)$ & $0(0 \%)$ & $4(0.8 \%)$ & .3 \\
\hline Urgent operation (no.) & $6(33.3 \%)$ & $62(40 \%)$ & $98(39.6 \%)$ & $170(44 \%)$ & $136(47.3 \%)$ & $213(42.9 \%)$ & .442 \\
\hline EuroSCORE (mean $\pm \mathrm{SD}$ ) & $2.8 \pm 1.8$ & $3 \pm 2$ & $3.4 \pm 1.9$ & $3.6 \pm 2.1$ & $3.5 \pm 1.8$ & $3.5 \pm 1.9$ & .077 \\
\hline Left main disease (no.) & $4(28.5 \%)$ & $26(23.2 \%)$ & $32(13.2 \%)$ & $100(27.6 \%)$ & $66(26.5 \%)$ & $129(26.6 \%)$ & .002 \\
\hline Coronary artery disease (vessels, mean $\pm \mathrm{SD}$ ) & $2.2 \pm 0.8$ & $2.4 \pm 0.7$ & $2.4 \pm 0.7$ & $2.5 \pm 0.7$ & $2.5 \pm 0.7$ & $2.5 \pm 0.6$ & .162 \\
\hline
\end{tabular}

